\title{
AUGUSTO DE CAMPOS: NOTAS SOBRE POEMAS DIGITAIS DO LIVRO OUTRO (2015)
}

\author{
Francisco Fábio Vieira Marcolino*
}

\begin{abstract}
Resumo: Este artigo faz uma leitura dos poemas "palavras" e "osso" de Augusto de Campos, que foram recolhidos no livro Outro (2015) e disponibilizados em sites da internet. Nossa abordagem se apoia nos estudos da Semiótica da Cultura e no procedimento da semiótica aplicada, no qual o próprio texto sugere relações estéticas e extraestéticas, evitando-se o uso descontextualizado do objeto artístico para a ilustração de teorias pré-estabelecidas. A análise articula a investigação da palavra poética e das linguagens acionadas no ambiente digital, marcado pela não linearidade e pela não hierarquia entre os códigos. Os poemas em foco promovem um diálogo intertextual com a obra poética de Augusto de Campos, através do uso da concisão, da metalinguagem e do minimalismo. A leitura e a fruição dos poemas estão condicionadas à interação entre o leitor e o suporte computador, e é a partir deste diálogo que investigamos o enriquecimento de sentidos textuais, promovido pela exploração criativa dos recursos da animação digital e da tradução intermídia. Durante a leitura são acionadas as reflexões teóricas de Lotman (1998), Chklovski (2013), Lucia Santaella (2003) e Jorge Luiz Antonio (2010) e Amador Ribeiro Neto (2015). Os poemas "palavras" e "osso" configuram um gesto de ressignificação da tecnologia através da apropriação poética e da plasmação de uma pulsão lírica em suporte digital.

Palavras-chave: Poesia brasileira dos anos 2000. Augusto de Campos. Poesia digital. Ressignificação da tecnologia.
\end{abstract}

\begin{abstract}
This article proposes a reading of the poems "palavras" and "osso" from Augusto de Campos, which were gathered in the book Outro (2015) and made available in websites. Our approach supports itself on the semiotics of culture studies and in the applied semiotics procedures, in which the text itself suggests aesthetic and extra-aesthetic relations, avoiding the non contextualized use of the artistic object only to illustrate pre-established theories. The analysis articulates the investigation of the poetic word and the triggered languages in the digital environment, marked by the non linearity and the non hierarchy between codes. The focused poems propitiate an intertextual dialogue with the poetic work of Augusto de Campos by the use of conciseness, metalanguage, and minimalism. The reading and the enjoyment of the poems are restricted to the interaction between the reader and the computer media, and it's from this dialogue the we investigate the enrichment of textual senses, promoted by the creative exploration of the resources of computer animation and the intermedia translation. During the reading the theoric reflections are triggered by Lotman (1998), Chklovski (2013), Lucia Santaella (2003) and Jorge Luiz Antonio (2010) and Amador Ribeiro Neto (2015). The poems "palavras" and "osso" shape a resignifying gesture of the technology through the poetic adapting and molding of a lyrical pulse in digital media.
\end{abstract}

Keywords: 2000s Brazilian poetry. Augusto de Campos. Digital poetry. Resignification of technology.

\section{Semiosfera e zona de fronteira}

Para amparar nossa leitura, iremos buscar apoio na Semiótica da Cultura de extração russa e na obra do poeta, tradutor e ensaísta Augusto de Campos, nascido em 1931 e ainda em atividade na cena cultural brasileira. Ler a obra de Augusto de Campos oferece um amplo panorama dos diálogos entre a poesia e os outros códigos na clave da tradução intersemiótica. A vantagem de acionar a Semiótica da Cultura é a de não pretender ser uma teoria totalizante de todos os sistemas de signos, mas de se deter no processo da cultura, mais especificamente na relação sistêmica entre a língua natural (sistema modelizante primário) e os outros códigos artísticos e culturais: literatura, música, cinema, mito (sistema modelizante secundário).

Para a Semiótica da Cultura de extração russa, cuja projeção, a partir dos anos de 1960, se dá pela obra de Lotman, Uspenski, Roman Jakobson, e aqui no Brasil,

\footnotetext{
* Doutor em Letras pela Universidade Federal da Paraíba (UFPB). Professor adjunto na Universidade Federal do Rio Grande do Norte (UFRN). Endereço eletrônico: fabiovieiramarcolino@ gmail.com.
} 
principalmente, através dos estudos de Haroldo de Campos, Irene Machado, Antonio Risério, as trocas entre códigos acontece via zonas de fronteira.

Para Lotman, fronteira não é borda divisória, mas filtro tradutório dentro do espaço denominado propriamente semiosfera. Irene Machado nos diz que fronteira é "zona de liminaridade e espaço de trânsito, de fluidez, de contato entre sistemas semióticos." (MACHADO, 2003, p. 159). A fronteira é um dos mecanismos da cultura que reduz a entropia e o caos da sociedade, "transformando a informação (não-texto) em texto." Ainda segundo Irene Machado, "Do ponto de vista da biosfera e da célula, a fronteira é película cuja função é impedir a penetração de agentes internos no interior da estrutura. Na semiosfera, contudo, a fronteira tem a função de um filtro absorvente." Daí a ideia de texto poroso.

Esse processo de incorporar o que está no lado externo acontece em muitas formas. Quando Chico César, na canção "Mama áfrica" diz: "Mama África, a minha mãe é mãe solteira, e tem de fazer mamadeira todo dia, além de trabalhar como empacotadeira nas Casas Bahia" está incorporando um dado caótico do cotidiano, que muitas vezes se passa despercebido, e graças ao olhar do poeta e do seu trabalho com a linguagem tecno-artística coloca em circulação no sistema cultural uma imagem, uma emoção, uma ideia que podem ser acessados por qualquer um, além de dar voz a uma personagem à margem da história.

Para Irene Machado, os estudos e reflexões de Lotman configuram uma visão sistêmica da Semiótica da Cultura, baseada nos sistemas modelizantes. Dessa maneira, "Como a consciência do homem é uma consciência linguística todos os aspectos dos modelos sobrepostos à consciência, inclusive a arte, podem ser definidos como sistemas modelizantes secundários", esclarece Lotman (1978, p. 37). O desenvolvimento dessa "visão globalizadora de cultura" atingiu a ideia de "semiosfera": "espaço semiótico necessário para a existência e funcionamento da linguagem e da cultura com sua diversidade de códigos" (MACHADO, 2003, p. 164).

\section{Ressignificação da tecnologia via poesia digital}

Antonio Risério (1998) afirma que a escrita digital é uma reação à linearidade fonológica da escrita alfabética. Quando os artistas praticam e reivindicam uma liberdade dimensional da linguagem configuram uma reação à norma linear do código alfabético, e consequentemente uma reação ao pensamento lógico-linear. O autor aponta três contribuições promovidas pelo uso da tecnologia na feitura de poemas:

a) utilização em composição textual do conjunto ícone/ símbolo;

b) iconização da própria escrita e da semantização de elementos infravocabulares, através da exploração icônica da letra;

c) os dois processos concorrem para uma superação do modelo (ou norma) linear da escrita fonética, que durante séculos dominou, de modo incontestável, a paisagem textual do ocidente. (RISÉRIO, 1998, p. 159).

Risério ressalta as contribuições que as novas mídias promovem para o texto poético: "o que se procura é ampliar o arco das formas textuais expressivas. Transfigurar o sistema alfabético, subvertendo ou superando a cristalização espacial meramente linear dos conceitos verbais". (RISÉRIO, 1998, p. 185). 
Em Poesia digital: teoria, histórias, antologias, Jorge Luis Antonio (2010) faz uma análise minuciosa do desenvolvimento e evolução da tecnopoesia e da poesia digital, na qual ilumina a questão a partir de três enfoques: a teoria, a história e as antologias. Na parte dedicada à teoria, adota e amplia o termo "tecnopoesia", a partir dos conceitos de Funkhouser e Davino: "procedimento do poeta sintonizado com as tecnologias do seu tempo". Afirma que tecnopoesia "se serve dos recursos eletrônicodigitais da informática para ambientar a palavra no contexto potencial da sua verbovoco-moto-visualidade." (ANTONIO, 2010, p. 03).

Ressalta a atitude do poeta diante da tecnologia como aquele que "vai transformar as linguagens interagentes da poesia e da tecnologia em elementos estruturais comuns por meio da mediação sígnica, campo no qual o poeta vai intervir e produzir a tecnopoesia" (ANTONIO, 2010, p. 05). O autor destaca a importância da "negociação semiótica" que "ocorre no momento em que os signos da tecnologia passam a ser apropriados pelos signos da poesia. É a mediação sígnica por meio de uma interface entre tecnologia e a poesia" (2010, p. 09).

Reforça que as categorias desenvolvidas por Ezra Pound, a partir da linguagem verbal, (melopeia, fanopeia, logopeia), ganharam novas possibilidades com o advento da tecnopoesia e da poesia digital. Sai em defesa da poesia, e não dicotomiza a questão em vertentes antagônicas: poesia $<>$ poesia digital.

Ler uma tecnopoesia em qualquer meio é uma atividade semelhante à de abrir um livro e ler uma poesia verbal, ver uma poesia visual, ouvir uma poesia sonora, assistir a uma poesia performática, visitar uma instalação poética, acessar uma poesia eletrônica. Em todos esses procedimentos predomina uma atividade comum: a poesia. Independentemente do suporte, há a leitura da poesia, não importa de qual tipo seja. A palavra poética está presente em toda tecnopoesia e determina uma configuração espacial, básica, formadora. (ANTONIO, 2010, p. 15).

Reafirma a ideia de que a poesia está mais próxima da linguagem artística (música, artes visuais, escultura) do que da linguagem literária, apoiando-se nas reflexões teóricas de Pound Castro, Pignatari e Khouri. Ressalta que as negociações semióticas entre a linguagem artística e a poética podem ser verificadas sob os seguintes aspectos:

a) um design de formas oferecido pelas artes da palavra, da imagem, do som e da animação, que se torna a concretização da polivalência potencial da linguagem poética;

b) a riqueza da inter e da multidisciplinaridade como forma de combinação poética: I - a visualidade (espacialidade, forma, cor, luz, animação); II - a tridimensionalidade dos objetos e o espaço físico; III - os sons e suas aplicações tecnológicas. (ANTONIO, 2010, p. 24).

No diálogo entre as linguagens artísticas e poéticas, destaca o uso da espacialidade e da visualidade na comunicação poética.

Destaca o conceito de ciberespaço: "a formação de um hipertexto e de uma mentalidade que, pela primeira vez na história, integra no mesmo sistema as modalidades escrita, oral e audiovisual da comunicação humana." (CASTELLS apud ANTONIO, 2010, p. 38). Em seguida ressalta as qualidades do hipertexto: 
os componentes básicos do hipertexto - lexias, 'links' e a estrutura da página da web - permitem realizar aquilo que vários poetas, desde as vanguardas, procuraram fazer no espaço físico (bidimensional e tridimensional): liberar a poesia do meio impresso e lhe dar autonomia do diálogo 'direto' com as linguagens não verbais. (ANTONIO, 2010, p. 42).

Neste sentido, as vanguardas e as neovanguardas prepararam o campo do fazer artístico para o salto quântico da cibercultura, ampliaram as possibilidades de modelização inter(intra)códigos. Não se trata de maquinolatria, tecnolatria ou cienciolatria, antes o desejo de colocar a técnica a serviço da criação poética, argumento que não apresenta divergência entre as abordagens de Antonio Risério e Jorge Luis Antonio.

Em "O computador enquanto suporte da nova literatura", Amador Ribeiro Neto (2010) reflete sobre as mudanças tecnológicas geradas pelo computador e a influência na literatura, enquanto consumo e produção. Logo de início, traz a percepção da semioticista Lucia Santaella:

Dos anos 90 para cá, estamos assistindo a uma nova revolução que (...) provavelmente trará consequências antropológicas e socioculturais muito mais profundas do que foram as da revolução industrial e eletrônica, talvez ainda mais profundas do que foram as revoluções neolíticas. Trata-se da revolução digital e da explosão das telecomunicações, trazendo consigo a cibercultura e as comunidades visuais. (...) Na ciberarte (...) as tradicionais divisões de papéis entre emissor e receptor se ampliam sobremaneira, com a sua condição interativa, a tradição das artes expositivas-contemplativas e mesmo das artes participativas (apud RIBEIRO NETO, 2010)

Adverte que "com a mudança do meio de produção, ou da mídia de produção, se assim preferir-se, altera-se o modo de recepção do objeto literário.". Amparado em reflexões de Pedro Barbosa e Rui Torres, assinala que há um novo espaço para o desenvolvimento e fruição da literatura:

O texto animado, multimídia, interativo dos blogs, twitters, orkuts e etc., têm feito emergir uma literatura que, mais que em épocas precedentes, toma o leitor e a linguagem como vetores. O princípio norteador de $O$ jogo da amarelinha, os labirintos borgeanos, etc., agora são matéria concreta de uma nova escrita, dos manuscritos de computador. A poesia animada por computador, ao trazer para o universo da criação novos componentes como o efetivo movimento e a interatividade, abre portas e janelas para novos campos da criação. $\mathrm{O}$ que é altamente estimulante para a nova literatura - e em especial, para a nova poesia, a poesia digital (ou ciberpoesia, ou infopoesia - já que a terminologia ainda não foi fixada) (RIBEIRO NETO, 2010).

Ainda ressalta o caráter não linear do hipertexto, e aproxima-o da perspectiva rizomática e não hierárquica desenvolvida por Deleuze e Guatarri. Neste sentido, Amador Ribeiro Neto vê com otimismo os novos horizontes abertos pela ciberliteratura.

Em Turbilhões do tempo: notas e anotações sobre poesia digital, Amador Ribeiro Neto (2017, p. 87) nos diz que "as escritas hipertextuais estão gerando uma economia na escrita, mudando a língua, a linguagem, a literatura." E consequentemente a percepção do leitor, que é convidado a experimentar a fruição poética em textos 
(complexos) hibridizados com outras linguagens, em direção a uma comunicação panpoética.

\section{Concisão analógica em ambiente digital}

Desde os anos 1950 que o poeta Augusto de Campos faz uma atualização da linguagem poética, dentro e fora da literatura brasileira, apoiada em metodologia poudiana ao explorar a tradução, a crítica e a produção de poemas. Ainda sem os recursos liberados pelas máquinas tecnológicas, fez poemas com carbonos coloridos, quando elaborou o livro Poetamenos de 1953. O intuito era o de justapor vozes e de sugerir uma movimentação de tipos e cores na página tomada como unidade mallamairca, que só com o suporte computador, a partir dos anos 1990, conseguiria realizar. Devido a esse desejo de comunicar-se com o presente, com a atualidade de cada época, é que a poesia de Augusto de Campos já foi chamada de poética de antecipação por Lúcia Santaella, Lúcio Agra e Omar Kouri.

Não se trata de fetichizar cegamente os novos meios ou em acreditar que o dispositivo tecnológico irá fazer o poema em sua intensidade e beleza. $\mathrm{O}$ trabalho analógico com a palavra continua o mesmo, requer convívio, observação, estudo, intuição e um pouco de sorte. O diferencial recai no desejo de ressignificar a tecnologia. A obra de Augusto de Campos é paradigmática nesse enfrentamento, sob a ótica da resistência, abre-se algum espaço para ressignificar os suportes, desde dentro, a partir da apropriação criativa da tecnologia. Fato de rebeldia e juventude, de gosto de enfrentar a desova maquínica e alocar faíscas de poemas nas engrenagens da semiosfera, cada vez mais complexa.

Nesse sentido, configura-se uma poética de vanguarda, não mais configurada como uma luta modernista em combater uma tradição, mas em contexto pós-utópico, no qual não há sentido em defender movimentos teleológicos, de salvação, ou de querer mudar a vida de toda uma sociedade através das alterações nas convenções artísticas. Augusto faz vanguarda quando se insere no presente, e traduz a tradição inserindo-a em uma comunicação poética(analógica) sensível às tessituras culturais da atualidade(digital), em nosso caso específico, à mobilidade do hipertexto.

O livro Outro (2015) é composto por quarenta poemas distribuídos em três seções: outro: poemas (vinte e um poemas), intro: intraduções (dez poemas), Extro: outraduções (oito poemas) e o poema "deserrata", ironicamente isolado após as notas. $\mathrm{O}$ quarto livro de poemas de Augusto de Campos, na verdade uma coletânea, exige um leitor sem preconceitos estéticos, que seja capaz de se colocar na leitura dos poemas sem medo de ir para áreas da transpalavra: o plano gráfico, das imagens, da tipografia, dos diálogos intertextuais com múltiplos artistas, não só do campo das letras, e o viés intratextual da poesia augustiana, que desde 1953, com Poetamenos, tem habitado a hibridez da palavra com outros códigos e suportes. Quando os poemas se desdobram para o mundo da animação essa exigência se adensa, pois o contexto digital promove uma inclusão de nossa percepção em textos audiovisuais.

Em todas as três seções do livro há uma exploração da tipografia em direção à motivação das fontes, ativando o olhar na produção de sentido desde o primeiro contato com cada texto. O poema "deserrata", colocado intencionalmente após as notas, é uma chave de leitura, denuncia a necessidade de se ler a palavra e todo um contexto de artes gráficas: "onde se/ lê/ leia-se/ leia-se/ vê". Ou como já foi dito por Pignatari: ouver. Em Outro, o desejo verbivocovisual está pleno. É o índice de um movimento vitorioso dentro da literatura brasileira, inclusive com repercussão internacional, desde a década 
de 1950 até os dias de hoje, vale lembrar o recente prêmio recebido por Augusto de Campos, equiparado ao nobel de poesia.

Para se ler bem o Outro é imperativo deixar-se levar pelas sugestões tipográficas de cores, de silêncios e de pausas. O que foi dito como verbivocovisual nos anos 1950, agora recebe a potencialização dos meios, no sentido de adensar a função poética e permitir inusitadas hibridizações e concreções de linguagem. $\mathrm{O}$ poema "desumano" (CAMPOS, 2015, p. 15), à Apollinaire, projeta uma seta com a mancha gráfica, cujo ápice recolhe a palavra "des". Através da circularidade de leitura "des" (no topo) e "humano" (na parte inferior da página), lemos uma desconstrução de camadas para se chegar à palavra "humano", (inclusive com a diminuição gradativa do tamanho dos blocos de palavras). O poema sugere que para se chegar ao humano é preciso se desumanizar de muitas vozes, só assim chegar ao vazio de nós mesmos, iconizado pela letra "o" desprendendo-se da palavra "vers-o": "para vol/ ver a ser/ no nano/ uni vers/ o/ da minh/ a mudez// humano".

A palavra verso é projetada dentro de "universo", algo que problematiza a referência apenas no plano metalinguístico do universo das letras e das poéticas ligadas ao código linguístico. Esquecer todas as vozes, de todas as línguas, a fim de chegar à língua muda, bem própria do eu lírico, para então ser humano, mas antes ser desumano: "emude/ cer des/ umano".

Não só a poesia de Augusto, mas sobretudo ela, quando realiza seu minimalismo baseado em enigmas semióticos, tende a aproximar contrários, rasurar as identidades, indeterminar os princípios, desestabilizar certezas, dizer o não dito, comunicar o incomunicável, abrir a senda para o desconhecido.

No espaço deste artigo, iremos fazer apontamentos iniciais sobre dois poemas da primeira seção: "osso" e "palavras".

Fig. 1: poema "Osso"

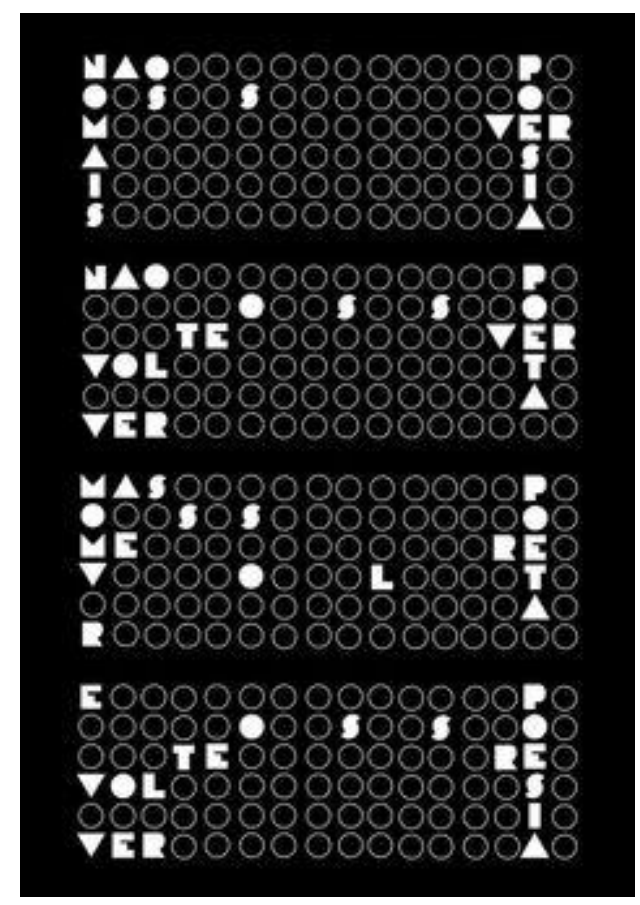

(CAMPOS, 2015, p. 19) 
O poema "osso" apresenta um campo semântico que faz intratextualidade com a obra de Augusto de Campos, principalmente ao tratar da metalinguagem através da palavra "osso" presente nos poemas: "João/agrestes", "SOS" e com destaque em "Sem saída" (CAMPOS, 2003, quarta capa): "Não posso ir mais adiante/ não posso voltar atrás".

A peça sugere a imagem de uma poesia substantiva, concisão, um prato magro condensado em linguagem contundente como quis Graciliano Ramos. Repare que a palavra osso é desentranhada de "pOSSO", assim como "pó" está contido em "posso".

O poema trabalha em pelo menos dois níveis de leitura uma horizontal e outra vertical. Assemelha-se a um jogo de palavras cruzadas ou mais verticalmente como um epitáfio para o poeta e para a poesia. Um verbo é obliquamente expandido "Volver" e "revolver".

Os dois verbos "revoltar" e "revolver" apresentam origens aproximadas. A palavra "revolver" vem do latim revolvere e significa: "revolver o espírito", e também "desenrolar um manuscrito, ler". O ato de revolver a poesia é o mesmo de revoltar-se. Fazer poesia, produzir poemas é revirar-se por dentro. Um ato significativo no qual há mudanças na linguagem e no sujeito. Esse processo de recriar-se e de insistir na não repetição foi apontado por João Cabral de Melo Neto ao publicar o poema "A Augusto de Campos" (MELO NETO, 2009, p. 27-28), o qual inicia seu livro Agrestes de 1985. Neste poema-homenagem, rico em síntese e em crítica, Cabral destaca o rigor e a inovação como características centrais da poesia de Augusto de Campos, uma poética de "distinta liga de aço" que consegue "lavar-se da que existia/ levá-la à pureza extrema".

"Volver", do latim volvere significa dar voltar, mudar de posição; do espanhol volver significa voltar a ser. A palavra é lembrada em contexto militar "meia-volta volver". Inserida nessa comunicação poética, a peça sugere a projeção de uma reflexão existencial, um balanço de vida, uma mudança de direção, e também, lateralmente, uma mudança de ponto de vista: "vol/ ver": vou ver.

Segundo Mukarovsky, "a denominação poética (que aparece num texto em que a função estética é dominante) não é determinada, em primeiro lugar, pela sua relação com a realidade significada, mas pelo modo de sua inserção no contexto." (1978, p. 160). Ao desviar o termo para outra situação comunicativa, o texto ganha outros significados. Não em contexto militar, com rigidez de direcionamentos, mas com uma conquista de explorar vários pontos de vista promovidos pelo trabalho com a palavra poética.

Há uma proliferação da palavra "osso" em vários sentidos da página, graças à diagramação inusitada dos círculos que se transformam na letra "o", de tal maneira que encontramos "osso" e "osso" na nona e décima segunda colunas, além de haver a projeção da palavra "so". Recolhendo o que foi semeado atingimos um trio de sintagmas paradigmáticos na poética minimalista de Augusto: "osso, só, pó". Cabe ao leitor explorar e projetar sua subjetividade nas múltiplas formas de ler o poema, tornando-se participante ativo da comunicação poética.

O poema "palavras", datado de 2000 , apresenta a seguinte imagem impressa: 
Fig. 2: poema "Palavras"

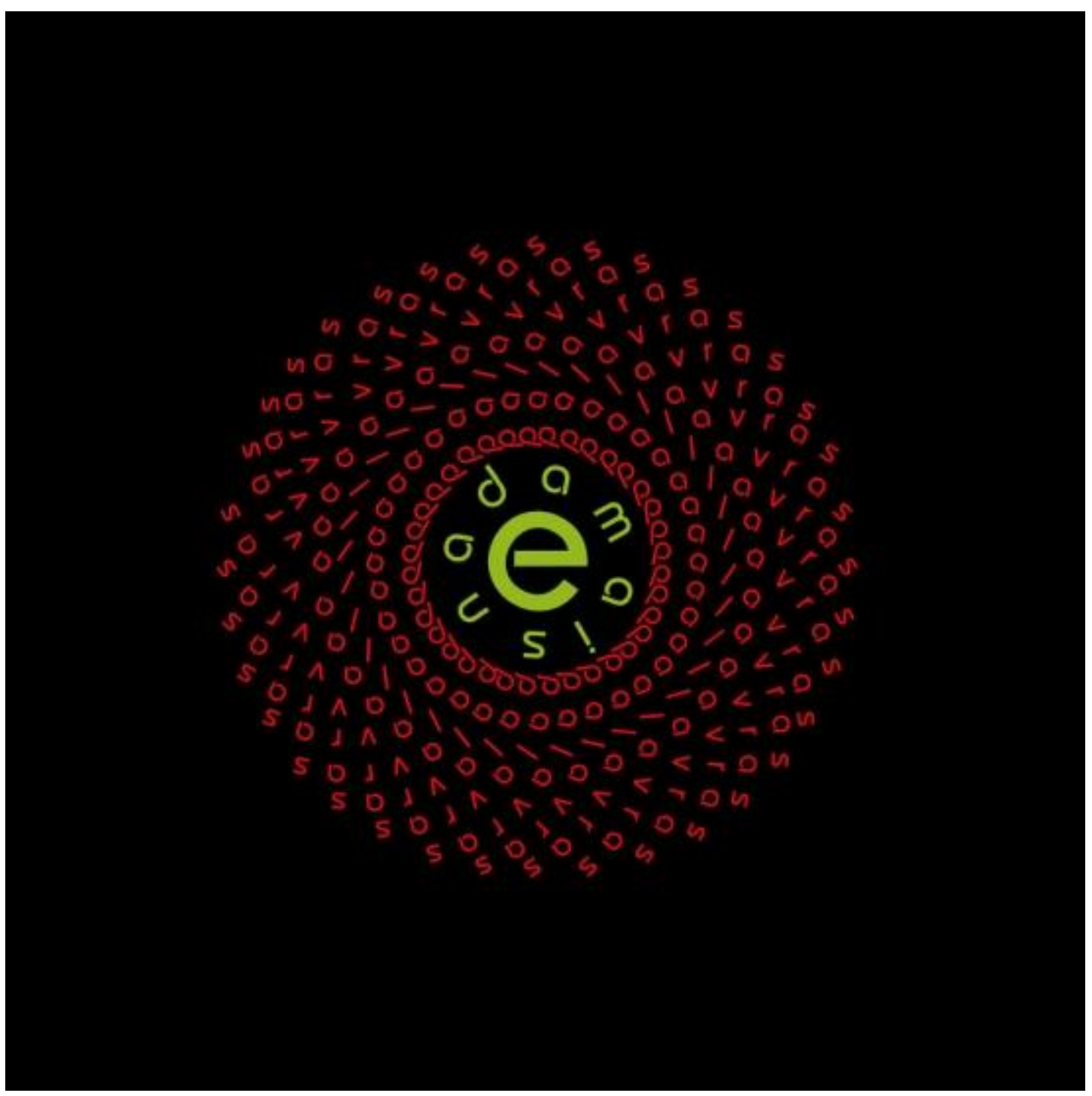

(CAMPOS, 2015, p. 17)

No plano mais explícito lemos: "palavras e nada mais", ecoa um ditado popular para sinalizar que aquela fala ou discurso nada vale, nada diz, são palavras apenas, sem nenhum significado. A forma espiralada do poema impresso ativa a leitura em círculos, fazendo com que nossos olhos percorram as várias esferas, inclusive o círculo central formado pela letra "e". Essa exigência de coautoria nos desautomatiza (cf. Chklovski, 2013) do sentido tradicional da linguagem discursiva: da esquerda para a direita, e de cima para baixo. Antes de atingirmos o nível mais explícito do plano verbal ("palavras e nada mais"), somos forçados a ler ludicamente, a participar desse jogo in-útil. Uma leitura apressada tende a inibir o poder de estranhamento, levando o processo para uma via sem polissemia, para a simplicidade sem densidade. Pular esse retardo duchampiano significa cair na ilusão de aparente facilidade construído pelo trompe-l'oleil semiótico.

Estas esferas iconizam uma mandala ou uma rosa. Ao ler o poema digital, visualizamos outras expansões semânticas: "poesia e nada mais / palavras e nada mais/ nada mais e". Ao girar as letras em sentido horário e anti-horário o poema torna mais visível a similaridade entre o "p" (palavras) e o "d" (nada), (recurso similar ao utilizado 
no poema bomba, recolhido em Não poemas (2003), no qual há tensão gráfica entre o "p" e o "b": poema-bomba).

Trata-se de uma ilusão de ótica. O poema deseja mostrar o encoberto. Um golpe de vista na percepção do leitor. Nosso olhar é enganado pelo trompe-l'oleil que desdobra as letras em múltiplas possibilidades no círculo central: "poesia, pó e nada mais"; "meu nada mais"; "poesia, meu deus, meu pó, meus ais, meu nada". Em "palavras" encontramos os termos "só" "pó", através do "s" invertido no final de "palavra" e na tensão do "a" em "o". O que acontece é uma retomada de um campo semântico minimalista bastante ativo na poesia augustiana. A letra 'E" rotacionada é um símbolo matemático de um quantificador existencial "existe". Dentro da lógica analógica do poema a letra quantifica o plano existencial do nada.

Através desse convite para ler as letras motivadas, encontramos a tensão entre a letra "a" convergindo para "o", de tal maneira que nos autoriza a ler o termo "poesia" em anagrama dentro do círculo interno (nada -E- mais)- (naPOEmAIS): "poesia palavra e nada mais".

O poema iconiza uma flor, na imagem estática. E o desabrochar de uma rosa na modalidade animação. A estrutura espiralada foi utilizada em outros poemas: "rosa doente", "SOS". No final da animação de dezesseis segundos atingimos a seguinte imagem:

Fig. 3: poema "Palavras", trecho da animação digital.

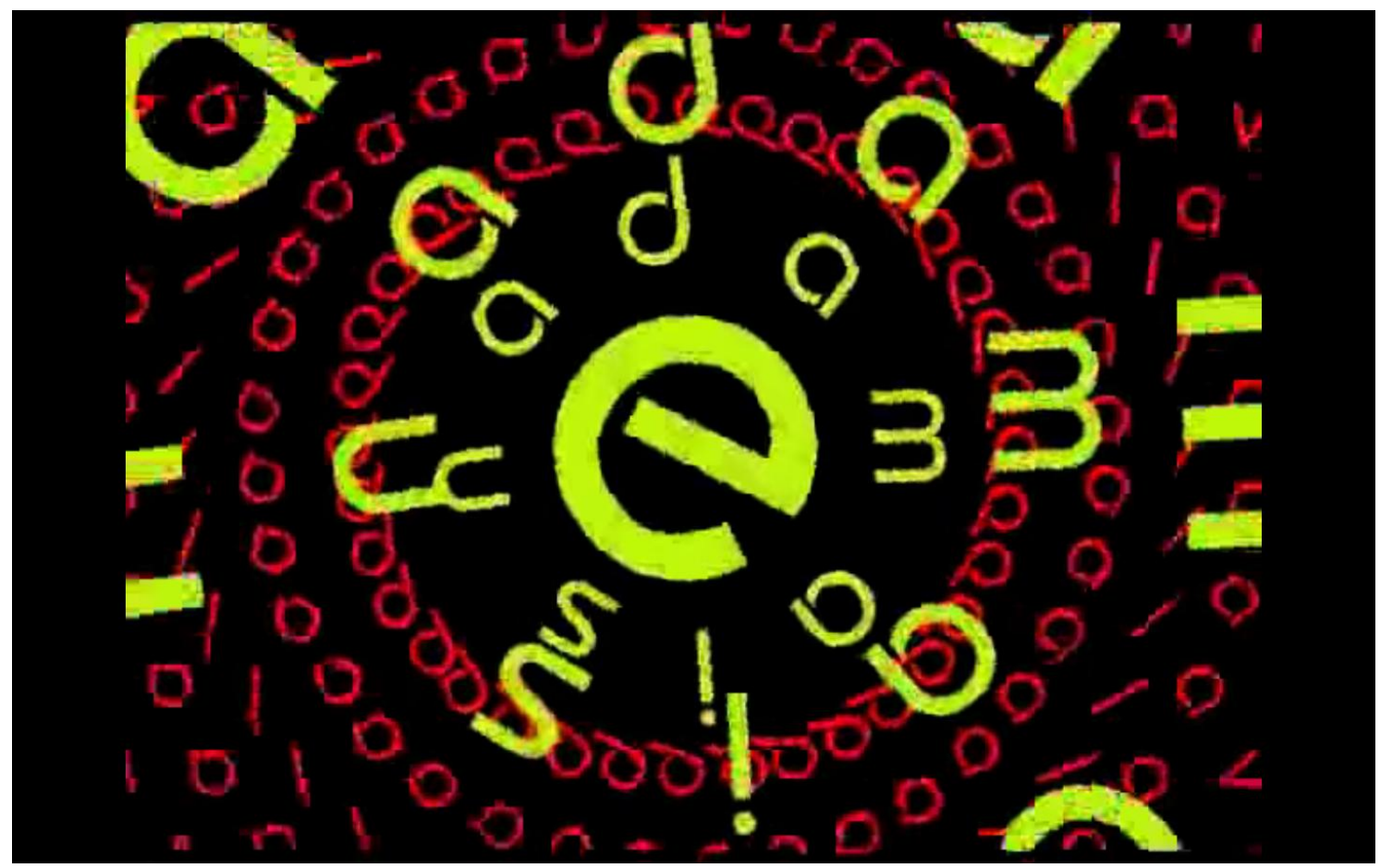

Disponível em: https://www.youtube.com/watch?v=OwVOhMhn4xA\&t=21s

O poema explora as qualidades do contexto digital através do movimento giratório e de expansão. Nessa tradução intersemiótica pode-se constatar que "o signo tecnológico deixa de ser pragmático, enquanto o signo poético torna-se mais polissêmico e interdisciplinar, sem perder a sua característica essencial." (ANTONIO, 2010, p. 20). A expansão semântica do núcleo amarelo é melhor visualizada no clip- 
poema quando flagramos: "meus ais" e "meu nada", além de trazer o eco dadaísta em "da da".

\section{Considerações finais}

O poema digital "palavras" comprova o pensamento de Jorge Luiz Antonio (2003, p. 03), pois o texto "se serve dos recursos eletrônico-digitais da informática para ambientar a palavra no contexto potencial da sua verbo-voco-moto-visualidade." Ao final desse roteiro de leitura fomos provocados em ler nos círculos expansivos de "palavras" o desdobramento da célula inicial "palavras e nada mais" em "meus ais meu nada". A enganosa aparência de simplicidade esconde uma dor existencial ("meus ais"), e nos sugere uma imagem da insignificância do nosso existir ("meu nada"). A poesia é palavra e nada mais que abriga meus ais e meu nada.

\section{Referências}

ANTONIO, Jorge Luiz. Poesia digital: negociações com os processos digitais: teoria, história, antologias. São Paulo: Navegar Editora; Columbus, Ohio, EUA; Luna Bisonde prods; FAPESP, 2010.

CAMPOS, Augusto de. Outro. São Paulo: Perspectiva, 2015.

CAMPOS, Augusto de. Não poemas. São Paulo: Perspectiva, 2003.

CHKLOVSKI, Victor. A arte como procedimento. In: TODOROV, Tzvetan (org.). Teoria da Literatura: textos dos formalistas russos. Trad. Roberto Leal Ferreira. São Paulo: Unesp, 2013.

LOTMAN, Iuri. A Estrutura do Texto Artístico. Trad. M. Carmo V. Raposo e A. Raposo. Lisboa: Estampa, 1978.

MACHADO, Irene. Escola de Semiótica: A Experiência de Tártu-Moscou para o Estudo da Cultura. Cotia, São Paulo: Ateliê, 2003.

MELO NETO, João Cabral de. Agrestes. Rio de Janeiro: Objetiva, 2009.

MUKAROVSKY, J. A denominação poética e a função estética da língua. In: TOLEDO, Dionísio (org.). Círculo Linguístico de Praga: estruturalismo e semiologia. Traduções de Zênia de Faria, Reasylvia Toledo e Dionísio Toledo.Porto Alegre: Globo, 1978.

RIBEIRO NETO, Amador. O computador enquanto suporte da nova literatura. Disponível em: http://sambaquis.blogspot.com.br/2010/09/o-computador-enquantosuporte-da-nova.html. Acesso em: 25 out 2017.

RIBEIRO NETO, Amador (org.). Turbilhões do tempo: notas e anotações sobre poesia digital. João Pessoa, Ideia, 2015.

RISÉRIO, Antonio. Ensaio sobre o texto poético em contexto digital. Salvador: Fundação Casa de Jorge amado; COPENE, 1998. 
Recebido em 28 de maio de 2018

Aceito em 23 de julho de 2018 